Nloma 2016, 34(1), 81-91

Revista de Psicologia, Ciències de l'Educació i de l'Esport

ISSN: $1138-3194$

Copyright (C) 2016

www.revistaaloma.net

\title{
Los contrarios en el aula de clase cuando se aprende a leer y a escribir
}

\author{
Claudia Portilla, Ana Teberosky \& Maribel Peró \\ Universidad de Barcelona
}

Rebut:6-7-2015

Acceptat:18-3-2016

\section{Los contrarios en el aula de clase cuando se aprende a leer y a escribir}

Resumen. En este estudio se analizan las producciones orales y escritas de listas de palabras contrarias de niños de 5 y 6 años, y su evolución después de una secuencia didáctica en el aula de clase. Las palabras contrarias fueron el contenido de aprendizaje cuando los niños aprendían a leer y a escribir siguiendo el criterio de que la eficacia de la enseñanza de la lengua aumenta cuando se apoya en las competencias lingüísticas de los alumnos. En el análisis, las producciones se describieron y compararon para determinar diferencias entre lo oral y lo escrito, y entre los momentos anteriores y posteriores a la intervención. En la secuencia didáctica se identificaron los procesos subyacentes al aprendizaje de las palabras contrarias. Los resultados muestran un incremento de vocabulario tanto en las tareas orales como en las escritas después de la intervención, con algunas diferencias entre modalidades que son descritas. Este incremento se interpreta a partir de los patrones expresados en las tareas de aprendizaje, su carácter encadenado y la evolución de las sesiones a través del trabajo con textos de literatura infantil que favorecieron la capacidad metalingüística y las posibilidades de escritura y lectura.

Palabras clave: contrarios; antonimia; lenguaje escrito; enseñanza; aprendizaje

The use of opposites in the classroom when learning reading and writing

Summary. This study is an analysis of the written and oral production of lists of opposite words by children from five to six years of age and of the evolution of this production after a session of classroom instruction. In application of the principle that the efficacy of language teaching increases when it is based on students' linguistic competencies, opposite words were used as the learning content when teaching the children to read and write. The analysis features descriptions and comparisons of the students' language production with the aim of identifying differences between oral and written productions and between before and after the intervention. The classroom session led to the identification of the processes underlying the learning of opposite words. The results show an increase in vocabulary in both the oral and the written tasks after the intervention, with these two types of tasks displaying certain differences, described in the text. This increase is interpreted in light of the patterns exhibited in the learning tasks, their linked and sequential nature and the evolution of the sessions through work with children's literary texts that favour metalinguistic capacity and the possibilities of reading and writing.

Keywords: opposites; antonyms; written language; teaching; learning

Correspondencia

Claudia Portilla

Departamento de Psicología Evolutiva y de la Educación

Universidad de Barcelona

Pg. Vall d'Hebrón, 171

08035 Barcelona

email: cportilla@ub.edu 


\section{Introducción}

Las palabras contrarias, o antónimos, denotan relaciones de oposición que exigen al hablante considerar conceptualmente la posibilidad de dos aspectos diferentes, pero a la vez interdependientes. Por ejemplo, «largo» solo puede ser considerado si se tiene en cuenta el contraste efectivo con su par contrario «corto» dentro de la dimensión conceptual de longitud. Esta particularidad de «oposición e interdependencia» ha generado un gran interés en el campo de la lingüística y de la psicolingüística. Desde la lingüística, la perspectiva clásica de Lyons (1977) considera que los contrarios se organizan según propiedades y relaciones de espacio y tiempo, de movimiento de los objetos y de acciones del sujeto, de procesos y posturas, y de valores cuantitativos y cualitativos, y categoriales del mundo. $\mathrm{Y}$ desde la lingüística cognitiva, Croft y Cruse (2008) sostienen que los contrarios no son solo una relación semántica entre ítems léxicos, sino que expresan una relación dinámica construida cognitivamente por los hablantes. Por su parte, Paradis y Willners (2011) entienden los contrarios como un fenómeno de contraste binario común en todos los tipos de modalidades comunicativas y registros, tanto escritos como hablados. Para estas autoras, el contraste binario es un principio extremadamente poderoso en la organización de la percepción y la cognición, y además, una herramienta eficiente en la argumentación, la narración, la explicación y la descripción.

Desde la adquisición del lenguaje se ha mostrado que los contrarios ayudan al niño pequeño en la comprensión del lenguaje del adulto. Por ejemplo, Clark (1993) propone el principio de contraste lexical como una fuente de información para entender la intención comunicativa de los adultos en el que los niños asumen para cada forma oral un significado diferente. En el caso de los contrarios, el niño descarta que «largo»y «corto» sean lo mismo, pero crea a la vez una representación conceptual de interdependencia de esos dos estados. Así, en una situación comunicativa, la producción de contrarios por parte del adulto ayuda al niño a comprender formas referenciales y a ver cómo se relacionan. Tomasello (2003) abunda en la argumentación, y encuentra que los contrarios ayudan al niño en la identificación de los referentes, en la especificación y en la extensión del significado de las palabras.

Otros autores también han señalado la precocidad de la comprensión de las relaciones de contrarios. Por ejemplo, Kagan (1984) afirma que a los niños no hay que enseñarles los contrarios explícitamente, sino que parecen esperar encontrarlos. Los estudios de Carey (1978) y Murphy y Andrew (1993) demuestran también que los niños entienden la polaridad de los adjetivos desde edades tempranas y que los pares de términos antónimos son aprendidos rápidamente.

En cuanto a la producción, Clark (1972) evidenció que los niños de entre 4 y 5 años, antes de aprender el significado de las palabras en un juego de palabras, ya muestran habilidades para decir contrarios. Asimismo,
Blanche-Benveniste y Ferreiro (1988) mostraron que los niños de 4 y 5 años, en una situación de juego, respondieron mayoritariamente con contrarios cuando se le pedía «decir algo al revés». Clark, Carpenter y Deutsch (1995) encontraron que, desde los 4 años, los niños pueden expresar funciones semánticas de negar o corregir una acción por medio de contrarios. De una manera más incipiente, se ha visto que, incluso cuando los niños todavía no mantienen en su léxico una pareja de contrarios, pueden incluir la negación a manera de precursor de uno de los pares de contrarios («caliente» / «no caliente»). Paradis y Willners (2006) interpretan la negación como una marca incipiente y previa a la adquisición de los contrarios lexicales (por ejemplo, «no caliente», interpretado como «está frío»).

Por otra parte, varios autores han señalado el papel relevante de los contrarios en el input del lenguaje que los adultos dirigen a los niños, como también en la estructuración de sus ideas y del discurso, incluso desde la edad de los 2 años (Jones, 2002; Jones \& Murphy, 2005). Además de frecuentes en el uso de los adultos en la conversación cotidiana, los contrarios también aparecen en los juegos verbales y en las canciones, en los cuentos y en las retahílas (Murphy \& Jones, 2008).

Como se ha visto, la precocidad en la comprensión y producción de los contrarios ha sido robustamente demostrada en estudios lingüísticos y evolutivos atendiendo a un carácter más bien sintagmático de aparición. Es decir, haciendo énfasis en la presencia de contrarios en el discurso cotidiano como en las locuciones «esto no está ni frío ni caliente», «has de subir y después bajar». Sin embargo, algunos autores han proclamado el carácter paradigmático de los contrarios aludiendo a que es una unidad aislable en el discurso y que puede constituir una representación aislada y potencialmente «emparejada» con otra realización lingüística. Por ejemplo, «frío/caliente, subir/bajar, negro/blanco» forman un conjunto de ítems lexicales en pareja que es posible disponer en una lista propia del sistema estructural de la lengua. Esta potencialidad de organización en un eje paradigmático aumenta la atención sobre la unidad diádica en sí misma e implica una ayuda lingüística en el aprendizaje de vocabulario y la evolución de la capacidad metalingüística.

Nelson (1977) encontró que este cambio de preferencia a respuestas paradigmáticas se daba alrededor de los 5 o 6 años y lo denominó «cambio sintagmáticoparadigmático», sugiriendo que la evolución en las respuestas de los niños demostraba un avance conceptual, que se explicaba por factores evolutivos de la cognición. Otros autores, como Cronin (2002) y Watson (1995), en cambio, han invocado la influencia de factores metalingüísticos y de aprendizaje del lenguaje escrito en el cambio sintagmático-paradigmático. Por ejemplo, Cronin (2002) encuentra relaciones significativas entre el nivel de lectura y las respuestas paradigmáticas de los niños, independientemente de su edad mental y cronológica, y argumenta que el aprendizaje de la lectura y escritura promueven el cambio lingüístico y conceptual. Con este argumento se evidencia 
que los contrarios pueden constituir también respuestas avanzadas en el plano paradigmático cuando se produce una lista exhaustiva, por ejemplo, en tareas complejas de inventarios de vocabulario alrededor de los 6 años, y que ello coincide con el aprendizaje del lenguaje escrito.

En conclusión, las aportaciones lingüísticas y psicolingüísticas indican el caso de los contrarios como una de las más robustas relaciones léxico-semánticas en la organización del vocabulario y en la organización del discurso (Cruse, 1986; Muehleisen, 1997; Fellbaum, 1995; Jones, 2002; Murphy, 2003; Croft \& Cruse, 2008). En el nivel léxico, el niño refuerza la asociación entre las dos formas de contrarios, en el semántico aprende las diferencias mínimas relevantes y, a nivel conceptual, usa categorías de oposición que organizan el mundo en dicotomías del tipo «cosas buenas y cosas malas», «cosas grandes y cosas pequeñas» (Murphy \& Jones, 2008). En relación con el avance conceptual, Llach y De Ribot (2010) encontraron que, cuando se plantea una tarea de elección entre diferentes estímulos graduados de mayor a menor oposición, los niños de entre 5 y 6 años prefieren de manera mayoritaria los contrarios en comparación con los adultos. El hallazgo se interpretó como un indicador de progreso en el aprendizaje conceptual debido a que los contrarios potencian el contraste y la comparación.

Todos los argumentos anteriores llevan a considerar los contrarios como un dispositivo muy precoz en la organización lexical y como un mecanismo cognitivo primitivo (Cruse, 2010), puesto que los humanos mostramos una tendencia a categorizar el mundo en contrastes dicotómicos (Lyons, 1977). En cambio, el argumento de la relación con el aprendizaje de la lectura y la escritura da una explicación más tardía de la organización exhaustiva del vocabulario en términos paradigmáticos. Esta relación puede explicarse también a través de una de las más primitivas funciones de la escritura: las listas escritas como un dispositivo que organiza y categoriza el conocimiento del mundo, desde las primeras escrituras sumerias. Tal como ha mostrado Goody (1977), las listas y el ejercicio paradigmático de hacer inventarios dentro de un dominio han sido un recurso propio de lo escrito. Recurso que, como otros autores sostienen, también juega un importante papel en el aprendizaje temprano del lenguaje escrito (Sepúlveda \& Teberosky, 2008).

Aunque hay una aceptación general creciente de la relación recíproca entre vocabulario y aprendizaje inicial de lo escrito (Justice, Meier \& Walpole, 2005; Sénéchal, 1997; Sénéchal, 2006; Sénéchal \& LeFevre, 2014), pocos son los estudios que aprovechan esta función específica de las listas escritas, así como tampoco los contrarios como contenido del aprendizaje de lo escrito. Uno de estos estudios (Teberosky \& Portilla, 2011) propone la incorporación de los contrarios como contenido de la alfabetización inicial, con el argumento de favorecer respuestas de carácter paradigmático en los niños que están aprendiendo a escribir y facilitar un tipo de trabajo metalingüístico para la producción de las listas escritas. En este estudio se puso en evidencia la facilidad de los niños (de entre 5 y 7 años) para producir listas escritas de contrarios, a partir de la lectura en voz alta por la profesora y del análisis de libros de literatura infantil cuya temática principal eran los contrarios. En dicho estudio se describieron las actividades didácticas y se analizaron las producciones escritas posteriores a las actividades de aprendizaje, lo que demostró que los niños de 7 años recuperaban la casi la totalidad de los contrarios presentados en el modelo y, además, producían contrarios nuevos en listas escritas de pares de opuestos. Sin embargo, no se ofreció una descripción del nivel de conocimiento de los contrarios de los alumnos antes y después del desarrollo de la secuencia didáctica (SD), como tampoco una comparación de esos cambios en el aprendizaje entre las producciones orales y escritas. Este aprendizaje resulta interesante desde las posiciones que argumentan la interdependencia entre lo oral y lo escrito, y sus relaciones con en el proceso de alfabetización (Sulzby, 1996; López-Orós \& Teberosky, 1998; Ferreiro, 2002).

En el presente estudio se pretende analizar los cambios en las producciones orales y escritas de listas de contrarios antes y después de una intervención didáctica en el aula de clase, que incorpora a los contrarios como contenido de aprendizaje. El marco general del programa en el que se inscribió el estudio consideraba decisivo el trabajo explícito sobre el vocabulario como un aspecto que permite comprender, describir, categorizar y analizar las entidades del mundo, y aprender y manipular las relaciones del lenguaje en sí mismo. En definitiva, una perspectiva metalingüística que potencia el aprendizaje del vocabulario y el aprendizaje del lenguaje escrito a través del vocabulario.

\section{Método}

\section{Participantes}

En el estudio participaron 25 niños de entre 5 y 7 años, pertenecientes a un grupo de tercer curso de Educación Infantil (parvulario de 5 años - P5) y a otro de primer curso de Educación Primaria de una escuela de la ciudad de Barcelona en la que se realizaba un proceso de asesoramiento e intervención psicopedagógica para la mejora de la enseñanza de la lengua escrita. Se trata de una escuela de titularidad pública en la zona de Ciutat Vella y en la cual la lengua que vehiculiza los aprendizajes es el catalán. Se siguieron como criterios de inclusión que los niños a) hubieran seguido las actividades diseñadas de intervención en el aula; b) a todos ellos se les administrara las tareas individuales de producción de contrarios de manera oral y escrita, antes y después de la intervención; c) no presentaran dificultades de adquisición del lenguaje por razones idiomáticas familiares; y d) no presentaran dificultades en el aprendizaje de la lengua escrita. Estos dos últimos criterios fueron consensuados con las maestras de aula y, además, como técnicas de selección de la muestra, se llevó 
Tabla 1. Descripción de los participantes según curso, género, edad, nivel de escritura y vocabulario

\begin{tabular}{|c|c|c|}
\hline \multicolumn{3}{|c|}{$\mathrm{n}=25$} \\
\hline \multirow{2}{*}{$\begin{array}{l}\text { Nivel } \\
\text { escolar }\end{array}$} & Parvulario de 5 años & 13 \\
\hline & Primero de Primaria & 12 \\
\hline \multirow{2}{*}{ Género } & Niños & 12 \\
\hline & Niñas & 13 \\
\hline \multirow{3}{*}{ Edad } & & Rango 65-86 meses (5; 5-7; 2 años) \\
\hline & & Media 74.96 meses ( $6 ; 2$ años) \\
\hline & & DS 6.96 \\
\hline \multirow{6}{*}{$\begin{array}{l}\text { Nivel de } \\
\text { vocabulario }\end{array}$} & & Puntuación derivada de test Peabody \\
\hline & & Media 96.48 \\
\hline & & DS 19.60 \\
\hline & Puntuaciones bajas & 3 \\
\hline & Puntuaciones medias & 16 \\
\hline & Puntuaciones altas & 6 \\
\hline \multirow{3}{*}{$\begin{array}{l}\text { Nivel de } \\
\text { escritura }\end{array}$} & Alfabético & 17 \\
\hline & Silábico-alfabético & 3 \\
\hline & Silábico & 5 \\
\hline
\end{tabular}

a cabo un proceso de evaluación del nivel de vocabulario y de conocimiento de la lengua escrita, excluyendo de la muestra a los niños y las niñas que presentaron puntuaciones muy bajas en el nivel de vocabulario y un nivel presilábico de la lengua escrita. Se obtuvo el consentimiento informado de las familias de los niños y las niñas para que participaran en este estudio. La Tabla 1 presenta la descripción de los participantes.

\section{Instrumentos}

Como instrumentos de obtención de la información, en primer lugar, se utilizaron los referidos a establecer los criterios de inclusión y exclusión de los participantes: a) el test de vocabulario en imágenes Peabody en su versión española (Dunn, 1985) y b) la categorización del nivel de conceptualización de escritura a partir de la propuesta clásica de Ferreiro y Teberosky (1979). En segundo lugar, los instrumentos referidos a la evaluación del conocimiento de contrarios antes y después de la intervención educativa, que se concretaron en listas espontáneas en formato escrito y oral por parte de los participantes.

Sobre las técnicas para conformar la muestra de este estudio, se obtuvo la puntuación derivada del nivel de vocabulario de cada niño a través de la adaptación al español del Peabody Picture Vocabulary Test-Revisado (PPVT-R, versión inglesa breve de Dunn y Dunn, 1981) y que es ampliamente utilizado para valorar el vocabulario comprensivo y la aptitud verbal en sujetos de entre 2 y 90 años. Esta es una prueba en la que el sujeto debe indicar qué ilustración representa mejor el significado de una palabra dada por el examinador. El coeficiente de fiabilidad de la consistencia interna del test completo (fórmula dos mitades con la corrección de Spearman-Brown) es de .96 (Dunn \& Dunn, 1981).

La categorización del nivel de conceptualización de escritura consistió en una entrevista individual en la que se presentaban dibujos de animales y se le pedía
Tabla 2. Criterios de categorización de los niveles de conceptualización de la escritura en el proceso de alfabetización

\begin{tabular}{ll}
\hline Escritura presilábica & $\begin{array}{l}\text { Los niños y las niñas de este nivel no intentan } \\
\text { establecer correspondencias entre las letras y los } \\
\text { sonidos cuando escriben o cuando leen su propia } \\
\text { escritura. Se incluyen las producciones sin } \\
\text { diferenciación gráfica para las diferentes palabras, } \\
\text { con una atribución de significado que viene } \\
\text { marcada por la intención subjetiva del autor. Se } \\
\text { incluyen también las escrituras con una } \\
\text { diferenciación gráfica incipiente, pero objetiva (en } \\
\text { la cantidad o en la variedad de letras). }\end{array}$ \\
\hline Escritura silábica & $\begin{array}{l}\text { Se incluyen las producciones con control de la } \\
\text { cantidad de letras en función de la cantidad de } \\
\text { sílabas de la palabra. Las letras pueden o no recibir } \\
\text { un valor sonoro convencional. En algunos casos, } \\
\text { el niño o la niña usa letras apropiadas, en otros } \\
\text { casos, cualquier letra sirve para representar la } \\
\text { sílaba oral. }\end{array}$ \\
\hline Escritura silábico- & $\begin{array}{l}\text { Los niños y las niñas de este nivel recurren a un } \\
\text { análisis silábico, escribiendo una letra para cada } \\
\text { sílaba, y a un análisis intrasilábico hasta llegar a } \\
\text { los fonemas. Las escrituras mantienen una } \\
\text { combinación de representaciones para sílabas y } \\
\text { fonemas. }\end{array}$ \\
\hline Escritura alfabética & $\begin{array}{l}\text { Las producciones en este nivel presentan una } \\
\text { correspondencia sistemática entre las letras y los } \\
\text { sonidos, aunque la ortografía no sea convencional. }\end{array}$ \\
\hline
\end{tabular}

al niño la denominación y descripción oral (¿qué es esto?, ¿qué está haciendo?) y a continuación que escribiera el nombre. Los estímulos utilizados tenían diferente estructura silábica y se incluyó también una frase según el nivel de escritura de los niños. Los estímulos fueron: «pez», «perro», «jirafa», «mariposa» $y$ «el perro come huesos». Siguiendo la propuesta clásica de Ferreiro y Teberosky (1979), las escrituras se analizaron siguiendo los criterios de cuatro niveles evolutivos: presilábico, silábico, silábico-alfabético, y alfabético (ver la adaptación de Portilla, Peró y Teberosky (2009) en la Tabla 2).

\section{Procedimiento}

La investigación que se expone en el presente artículo formó parte de un programa de asesoramiento e intervención psicopedagógica en el Centro de Educación Infantil y Primaria Àngel Baixeras, que concebía la temática del aprendizaje de vocabulario como un componente fundamental en la alfabetización inicial. De manera específica, se llevó a cabo un estudio basado en el diseño desde un paradigma de investigación acción y de colaboración universidad-escuela que se orienta a contribuir en la mejora de las prácticas educativas y en el avance de la construcción teórica acerca del aprendizaje (Cobb, Confrey, diSessa, Lehrer \& Schauble, 2003; Rinaudo \& Donolo, 2010). El grupo de investigadores de la Universidad de Barcelona ofreció, dentro del programa de asesoramiento, un conjunto de sesiones semanales de formación a los maestros de ciclo de Educación Infantil y Primaria. En este contexto, se diseñó y desarrolló, de manera conjunta, la SD que se llevó a cabo con materiales y actividades específicas para cada grupo escolar. De este modo, el estudio no obedeció a un estudio experimental canónico de prueba de hipótesis, sino a un diseño de intervención que incluyó técnicas mixtas de análisis y que, en última instancia, comportaba la búsqueda simultánea de la 
teoría a partir de la enseñanza y la innovación de la práctica educativa (De Corte, 2009).

La SD diseñada para la intervención incluía los contrarios como unidad de contenido del aprendizaje de vocabulario y de alfabetización inicial en actividades orales y escritas. Se diseñaron sesiones en las que las maestras proponían tareas específicas de enseñanza y aprendizaje, y en las que los niños observaron, analizaron, comentaron y manipularon material ilustrado y escrito, y generaron diferentes productos. Se concretaron siete sesiones de intervención para cada grupo, durante siete semanas del último trimestre del curso, todas las sesiones fueron registradas y transcritas para su análisis. Para valorar cambios en el aprendizaje, se fijaron tareas individuales de producción espontánea de contrarios en formato oral y en formato escrito antes y después de la intervención. Estas tareas de evaluación se llevaron a cabo en situación de entrevista individual fuera del aula habitual de clase.

\section{Las tareas de evaluación antes y después de la intervención}

Las tareas individuales de producción espontánea de contrarios en formato oral y en formato escrito siguieron el mismo protocolo en los dos momentos: antes y después de la intervención. Las primeras tareas se efectuaron una semana antes de iniciar la SD, y una semana después de terminarla se volvieron a repetir con un lapso de nueve semanas entre tareas. Estas tareas fueron llevadas a cabo por una investigadora de la universidad, la misma que acompañó a las maestras en las sesiones de la SD. De manera específica, se realizaron entrevistas individuales siguiendo el método de análisis reflexivo propio del enfoque histórico-crítico (o método clínico) de Piaget prescindiendo de conceptualizaciones lingüísticas en las preguntas y haciendo énfasis en las propias hipótesis y saberes del niño (Vuyk, 1981).

En la entrevista se pedía al niño que dijera todos aquellos contrarios que recordaba y, a continuación, se le pedía que los escribiera. En el desarrollo de la tarea antes de la intervención, la entrevistadora no introducía el término «contrario», sino que planteaba al niño un modelo para provocar la recuperación de pares de palabras contrarias de forma espontánea. Específicamente, se utilizó la consigna del apartado de la evaluación del conocimiento y comprensión de opuestos de la Prueba del Lenguaje Oral de Navarra revisada (PLONR) de Aguinaga, Armentia, Fraile, Olangua y Uriz (2004), que contempla frases del tipo: «si te digo "la sopa está caliente", "el helado está..."» y el niño debe completar con el contrario adecuado. De esta manera, se ofrecía un primer ítem de demostración siguiendo la propuesta del PLON-R y a continuación se introducía la consigna «dime cosas como "caliente/frío"». Si había dificultades de evocación o comprensión de la tarea se daban dos ejemplos más como demostración de lo que se pedía hacer (por ejemplo, «grande/pequeño, noche/ día»). Se consideró el criterio de abandonar la tarea a la falta de respuesta al tercer ejemplo, pero, de hecho, todos los niños respondieron.
En la condición escrita, se les pedía que escribieran a partir de la consigna «ahora vamos a escribir estas cosas que has dicho» sin la pretensión de que escribieran exactamente los pares de contrarios que ya habían dicho, sino como dispositivo para generar producción. No se hacía restricción en la disposición de la escritura en el papel, ni se presentó soporte visual para ninguna de las dos condiciones. La información se recogió a través de registros de audio y a partir de las propias escrituras de los niños para su posterior trascripción y análisis.

\section{El proceso de intervención}

Las maestras tutoras de cada grupo escolar diseñaron con asesoría del equipo de investigación de la Universidad cada una de las sesiones y las tareas de enseñanza y aprendizaje. Las tareas se planificaron en relación con seis textos que se concretaron como el input o material de aprendizaje, y que se seleccionaron a partir de un conjunto de libros de literatura infantil ilustrada teniendo en cuenta la calidad de las imágenes y la claridad de presentación de los contrarios. Se trataba de libros de imágenes que mostraban contrarios acompañados o no de las etiquetas escritas correspondientes a cada ilustración, o libros que planteaban narraciones y textos en forma de rima. Debido a que la lengua vehicular escolar es el catalán, todos los materiales fueron adaptados a esta lengua. En las Tablas 3 y 4 se muestran los materiales seleccionados para cada grupo y el tipo de actividad que se pretendía realizar en la SD.

Tabla 3. Textos de literatura infantil y actividades previstas en P5

\begin{tabular}{|c|c|c|}
\hline Material & Contenido & Actividades previstas \\
\hline $\begin{array}{l}\text { Texto } 1 \\
\text { Corte, M. \& Teberosky, A. } \\
\text { Contrarios. (sin publicar). }\end{array}$ & 15 pares de contrarios & $\begin{array}{l}\text { Lectura de imágenes o } \\
\text { visualización }\end{array}$ \\
\hline $\begin{array}{l}\text { Texto } 2 \\
\text { Haché, A. (2012). Dins } i \\
\text { fora. Barcelona: Cruilla. }\end{array}$ & $\begin{array}{l}15 \text { pares de contrarios } \\
\text { etiquetas e } \\
\text { ilustraciones }\end{array}$ & $\begin{array}{l}\text { Asociación de } \\
\text { vocabulario etiquetas / } \\
\text { imágenes }\end{array}$ \\
\hline $\begin{array}{l}\text { Texto } 3 \\
\text { Alcy (2005). Tô dentro, tô } \\
\text { fora. Belo Horizonte: } \\
\text { Formato Editorial. }\end{array}$ & $\begin{array}{l}12 \text { pares de contrarios } \\
\text { y } 12 \text { versos pareados }\end{array}$ & $\begin{array}{l}\text { Lectura de imágenes o } \\
\text { visualización } \\
\text { Lectura en voz alta } \\
\text { Dictado al adulto }\end{array}$ \\
\hline $\begin{array}{l}\text { Texto } 4 \\
\text { Heargraves, R. (2008). Little } \\
\text { Miss Contrary. Londres: } \\
\text { Egmont. }\end{array}$ & 25 pares de contrarios & $\begin{array}{l}\text { Dictado al adulto } \\
\text { Lectura } \\
\text { Comentar aspectos } \\
\text { metalingüísticos }\end{array}$ \\
\hline
\end{tabular}

Tabla 4. Textos de literatura infantil y actividades previstas en primero de Primaria

\begin{tabular}{|c|c|c|}
\hline Material & Contenido & Actividades \\
\hline $\begin{array}{l}\text { Texto } 1 \\
\text { Niño, J. A. (2003). La } \\
\text { señora contraria. Bogotá: } \\
\text { Panamericana. }\end{array}$ & 7 pares de contrarios & $\begin{array}{l}\text { Leer imágenes o } \\
\text { visualización } \\
\text { Lectura en voz alta }\end{array}$ \\
\hline $\begin{array}{l}\text { Texto } 2 \\
\text { Corte, M. \& Teberosky, A. } \\
\text { Contrarios. (sin publicar). }\end{array}$ & 15 pares de contrarios & $\begin{array}{l}\text { Leer imagen o } \\
\text { visualización } \\
\text { Lectura en voz alta } \\
\text { Comentar aspectos } \\
\text { metalingüísticos } \\
\text { Asociar etiquetas }\end{array}$ \\
\hline $\begin{array}{l}\text { Texto } 3 \\
\text { Alcy (2005). Tô dentro, tô } \\
\text { fora. Belo Horizonte: } \\
\text { Formato Editorial. }\end{array}$ & $\begin{array}{l}12 \text { pares de contrarios } \\
\text { y } 12 \text { versos pareados }\end{array}$ & $\begin{array}{l}\text { Lectura de imágenes o } \\
\text { visualización } \\
\text { Comentar aspectos } \\
\text { metalingüísticos }\end{array}$ \\
\hline $\begin{array}{l}\text { Texto } 4 \\
\text { Lobel, A. (2000). Ratolí } \\
\text { molt baix i ratoli molt alt. } \\
\text { Barcelona: Kalandraka. }\end{array}$ & 5 pares de contrarios & $\begin{array}{l}\text { Leer para escribir } \\
\text { Comentar aspectos } \\
\text { metalingüísticos } \\
\text { Lectura en voz alta }\end{array}$ \\
\hline
\end{tabular}


La selección previa de las actividades consideró el momento evolutivo y de aprendizaje de los dos niveles escolares. Las sesiones se llevaron a cabo en el aula habitual del curso escolar correspondiente.

\section{Análisis de los datos}

Inicialmente se analizaron las listas orales y escritas de contrarios antes y después de la intervención en el aula realizando dos tipos descripciones. Primero, la descripción cualitativa reveló si lo que habían producido los niños se trataba de un contrario convencional o de una producción sin una relación de oposición evidente. La descripción cuantitativa analizó los cambios en la producción de contrarios después de la secuencia didáctica y la comparación de las proporciones observadas en las producciones entre los niños de P5 y primero de Primaria en las dos tareas oral y escrita. Posteriormente se generó la descripción cualitativa de la evolución de la SD para cada uno de los grupos escolares a partir de la caracterización detallada de las sesiones. La descripción cualitativa tuvo en cuenta la producción de contrarios para cada uno de los dos grupos. La descripción cuantitativa tuvo en cuenta el número total de contrarios producidos para los dos grupos diferenciando entre la condición oral y la condición escrita.

\section{Descripción de las producciones de contrarios antes y después de la intervención}

En primer lugar, se realizó un conteo del número total de contrarios producido para cada una de las condiciones (oral y escrita) y se categorizó y codificó el tipo de respuesta según si esta era «convencional» con un 1 o «no convencional» (o sin relación semántica), con un 0. Para esta categorización se tuvo en cuenta la clasificación clásica de Cruse (1986) en la que se establece una diferenciación básica entre contrarios complementarios, graduables y reversibles. Los complementarios hacen referencia a opuestos que tienen propiedades mutuamente exclusivas (hombre/mujer, vivo/muerto). Los contrarios graduables se refieren a opuestos que tienen valores extremos en una escala (largo/corto, frío/ caliente). Los contrarios reversibles aluden a opuestos que marcan las dos direcciones a lo largo de un eje (dar/ recibir). De esta manera, por «convencional» se tuvo en cuenta esta tipología de contrarios, puesto que determina la presencia de un rasgo semántico común que pone de manifiesto la relación de oposición (por ejemplo, grande/pequeño). Por «no convencional» se consideraron aquellas producciones que no mostraban relación semántica (por ejemplo, radio/joya).

A partir de las producciones codificadas como «convencionales» se procedió a describir el tipo de convencionalidad al que hacía referencia la producción del niño, atendiendo a sus propios criterios de lo que para él era un «contrario». El proceso de codificación se llevó a cabo por parte de dos codificadores en el que el porcentaje de acuerdo fue del $97 \%$ y para aquellas producciones en que no hubo acuerdo, una tercera persona en calidad de juez experto revisó las producciones y marcó el criterio de categorización en cuanto a convencionalidad o no de la producción.

Cambios en la producción de contrarios antes y después de la intervención, y entre las condiciones oral y escrita de las tareas

Para determinar diferencias significativas en la producción de contrarios en las tareas antes y después de la SD se compararon las medias a través de una prueba $t$ de student de medidas repetidas. Asimismo, se analizó si existían diferencias estadísticamente significativas entre las dos condiciones oral y escrita en las tareas antes y después de la intervención también a partir del estadístico $t$ de student de medidas repetidas. Por otra parte, con el fin de estudiar si existían diferencias estadísticamente significativas en la variabilidad de la producción de las muestras, tanto para la condición oral como para la condición escrita, se obtuvo el estadístico F de Snedecor de igualdad de varianzas entre las tareas antes y después de la intervención.

La medida de variabilidad determina el grado de dispersión de la distribución de los valores obtenidos en las listas de contrarios orales y escritos. De esta forma, la variabilidad muestra si las puntuaciones obtenidas en relación con el número de contrarios total en las listas, tanto en la condición oral como en la condición escrita, están muy alejadas de la media obtenida. Con ello se sabe si todos los casos son parecidos o varían entre ellos. Por tanto, si la variabilidad es mayor, indicará heterogeneidad o distanciamiento en relación con la media, lo que mostrará menor uniformidad de los datos. Al contrario, si la variabilidad es menor, indicará homogeneidad o acercamiento a la media.

\section{Descripción de la evolución de la secuencia didáctica}

Este análisis se realizó a partir de la revisión de la trascripción de cada una de las sesiones para cada grupo, identificando en una línea temporal los fragmentos que caracterizaban la interacción entre la maestra y el grupo de alumnos, y la articulación de sus actuaciones basada en el trabajo explícito con los materiales ilustrados. Esta descripción se inspiró en el modelo del análisis de la interactividad propuesto por Coll, Onrubia y Mauri (2008). A partir de este análisis se caracterizó la funcionalidad de cada uno de los fragmentos identificando los procesos que intentaban promover el aprendizaje de vocabulario y del lenguaje escrito. En concreto, el procedimiento para describir la secuencia didáctica se desarrolló siguiendo los fundamentos generales del modelo de análisis mencionado. En un primer nivel, en el que se detectaron las formas de organización de la actividad conjunta a lo largo de la $\mathrm{SD}$, se identificaron los fragmentos que remitían a una estructura determinada y que mantenía una unidad temática dentro de la sesión. Así, cada sesión podía tener diferentes segmentos que variaban entre ellos en cuanto a contenido y duración. Una vez establecidos todos los fragmentos en cada una de las sesiones para 
los dos cursos, cada fragmento se etiquetó atendiendo a los procesos que activaban el análisis de los contrarios. Posteriormente a este análisis más «estático» dentro de las sesiones y a través de ellas, se procedió a analizar la evolución de los fragmentos en relación con su presencia/ausencia, frecuencia y distribución a lo largo de las sesiones y en el conjunto de la SD. En este estudio, el segundo nivel que describía el modelo de análisis consideró los mensajes entre los participantes en la configuración propia de cada fragmento etiquetado. De esta manera se elaboró una interpretación conjunta de los mensajes y de la naturaleza del fragmento para dar cuenta del conjunto de sesiones dentro del marco de la SD. La valoración de estos aspectos, tanto para P5 como para primero de Primaria, permitió configurar unos «mapas de interactividad»; es decir, una síntesis con los procedimientos más presentes durante la SD a partir de una interpretación global integrada del primer y del segundo nivel de análisis. A continuación se optó por establecer los patrones en cada uno de los grupos escolares, de los que se obtuvo una síntesis de los fragmentos etiquetados a lo largo de la SD.

\section{Resultados}

Descripción de las producciones de contrarios antes y después de la intervención

\section{Convencionalidad}

En primer lugar se encontró que el grado de convencionalidad fue bastante alto considerando el total de contrarios producidos por los dos grupos escolares antes de la SD, tal y como se muestra en la Tabla 5. En la tabla se muestra el porcentaje de convencionalidad para cada grupo escolar y para cada condición de la tarea de producción de contrarios antes y después de la SD. En la tabla también se observa que, en general, el número de contrarios convencionales aumentó después de la intervención. En la distribución cualitativa de las producciones se destaca que los niños de primero de Primaria realizaron más producciones tanto orales como escritas, y que las listas orales incorporaron un mayor número de contrarios en los dos grupos escolares.

Dentro de la categoría de convencionalidad, se incorporaron producciones desde contrarios conocidos o lexicalizados hasta producciones en las que el niño argumentaba un rasgo de oposición evidente y que provenían de su experiencia o de un nivel incipiente de comprensión de la oposición (por ejemplo, Tom/ Jerry, tranquilo/no tranquilo).

Cambios en la producción de contrarios antes y después de la intervención, y entre las condiciones oral y escrita

\section{Comparación de las tareas antes y después de la SD}

Para el análisis estadístico se realizó una comparación de las dos tareas antes y después de la SD, en cada una de las condiciones oral y escrita. En la condición oral, a partir de la prueba $t$ de student de medidas repetidas se encontraron diferencias significativas $(t=8.62$, g.l. $=24$ $\mathrm{p}<.001)$ que dejan ver un incremento significativo en la producción oral de contrarios antes de la intervención $(\bar{x}=2.32$; d.t. $=1.88)$ y después de la intervención $(\bar{x}=$ 11.24; d.t. = 5.42). Las diferencias que se encuentran entre una tarea y otra son relevantes si se valora el alto tamaño del efecto $(\mathrm{r}=.865)$, lo que confirma que los niños produjeron más contrarios después de la intervención en la tarea oral. Por otra parte, se observa mayor variabilidad en las producciones del total de niños. Es decir, las producciones en su conjunto fueron más homogéneas antes de la intervención que después de esta, diferencia que fue estadísticamente significativa ( $\mathrm{F}(24$, $24)=8.27, \mathrm{p}<.001$ ). En general, la producción oral de contrarios antes de la intervención fue baja pero homogénea y después de la intervención se marcó una variabilidad importante en las producciones.

En la condición escrita también se encontraron diferencias estadísticamente significativas entre las tareas antes y después de la intervención $(\mathrm{t}=4.74$, g.l. $=24 \mathrm{p}<.001)$ que evidencia un incremento marcado entre la producción de contrarios antes de la intervención $(\bar{x}=3.32$; d.t. $=2.54)$ y después de la intervención $(\bar{x}=6.72$; d.t. $=3.18)$ y una tendencia más homogénea en la producción antes de la intervención, aunque no resultó estadísticamente significativa $(\mathrm{F}(24,24)=1.56$, $\mathrm{p}=.281$ ). Las diferencias que se encuentran son también relevantes si se valora el tamaño del efecto ( $\mathrm{r}$ =.695), lo que confirma que los niños produjeron más contrarios después de la intervención en la tarea escrita. En esta condición escrita, hubo incremento en la producción de contrarios después de la intervención, pero en su conjunto, los niños se conservaron más homogéneos en esta modalidad, a diferencia de la variabilidad encontrada en la condición oral. Esta mayor producción de contrarios después de la intervención se convierte en indicador de un incremento en este tipo de vocabulario. En la Figura 1 se muestra la comparación de la variabilidad en las diferentes condiciones oral y escrita antes y después de la SD.

Tabla 5. Descripción del total de contrarios producidos en las tareas (antes y después de la intervención) y en las dos condiciones (oral y escrita)

\begin{tabular}{|c|c|c|c|c|c|c|c|c|}
\hline \multirow{3}{*}{$\begin{array}{l}\text { Total ítems producidos } \\
(\mathrm{f}=613)\end{array}$} & \multicolumn{4}{|c|}{ Preescolar P5 $(\mathrm{f}=271)$} & \multicolumn{4}{|c|}{ Primero de Primaria $(f=342)$} \\
\hline & \multicolumn{2}{|c|}{ Oral $(f=151)$} & \multicolumn{2}{|c|}{ Escrito $(f=120)$} & \multicolumn{2}{|c|}{ Oral $(f=203)$} & \multicolumn{2}{|c|}{ Escrito $(f=139)$} \\
\hline & $\operatorname{Pre}(f=24)$ & Post $(f=127)$ & Pre $(f=32)$ & Post $(f=88)$ & $\operatorname{Pre}(f=37)$ & Post $(f=166)$ & $\operatorname{Pre}(f=56)$ & Post $(f=83)$ \\
\hline Convencional & $83.3 \%$ & $96.9 \%$ & $93.8 \%$ & $93.2 \%$ & $91.9 \%$ & $95.8 \%$ & $91.1 \%$ & $94 \%$ \\
\hline Sin relación semántica & $16.7 \%$ & $3.1 \%$ & $6.3 \%$ & $4.5 \%$ & $8.1 \%$ & $4.2 \%$ & $8.9 \%$ & $6 \%$ \\
\hline
\end{tabular}




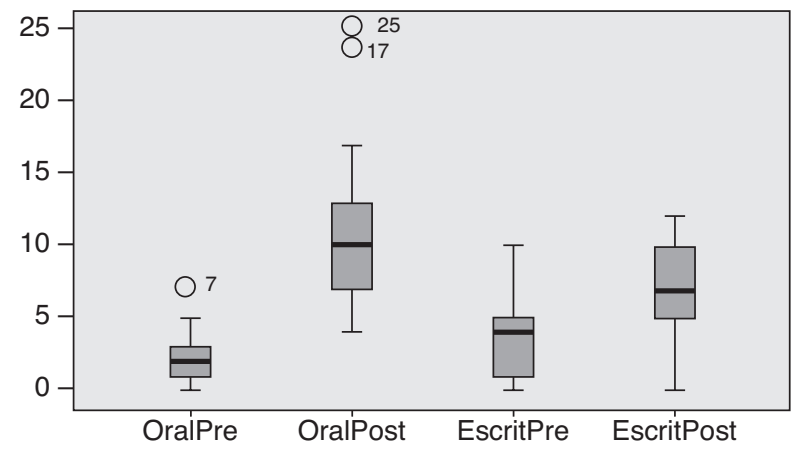

Figura 1. Variabilidad en la producción de contrarios en las tareas antes y después de la SD

\section{Comparación de las dos condiciones oral y escrita}

Los resultados evidenciaron diferencias estadísticamente significativas entre la condición oral y la condición escrita. Antes de la intervención, a partir de la prueba $t$ de student de medidas repetidas se encontraron diferencias significativas $(\mathrm{t}=3.01$ g.l $=24 \mathrm{p}=.006)$, que indican que la tarea escrita fue más productiva $(\bar{x}=$ 3.32 ; d.t. $=2.54)$ que la tarea oral $(\bar{x}=2.32$; d.t. $=1.88)$. Valorando el tamaño del efecto $(\mathrm{r}=.523)$ las diferencias son de relativa importancia, pues muestran que los niños produjeron menos contrarios en la tarea oral que en la escrita antes de la intervención.

Después de la SD, la tarea oral $(\bar{x}=11.24 ;$ d.t. $=5.42)$ resultó más productiva que la tarea escrita $(\bar{x}=6.72$; d.t. $=3.18)$, lo que fue estadísticamente significativo ( $\mathrm{t}$ $=5.6$ g.l. $=24 \mathrm{p}<.0001)$. Si se valora el tamaño del efecto, estas diferencias son de una gran relevancia ( $\mathrm{r}$ $=.753$ ), lo que evidencia que los niños produjeron más contrarios en la tarea oral que en la escrita después de la intervención.

\section{Descripción de la evolución de la secuencia didáctica}

Se evidenciaron dos patrones para cada uno de los grupos escolares relacionados con los textos seleccionados como input o material de aprendizaje, y el carácter encadenado de las tareas. En el caso de P5 se reveló la consolidación de dos fases durante las siete sesiones de aprendizaje (ver Figura 2). En la primera de ellas se concretó una serie de tareas encadenadas con el propósito de visualizar y describir los materiales ilustrados haciendo énfasis en la extracción de palabras contrarias y la asociación entre imágenes y vocabulario. En la segunda fase, las tareas dieron cuenta de un nivel más metalingüístico en relación con los tres textos de la primera fase, a partir de una situación de dictar a la maestra el listado de pares contrarios que los alumnos recordaban. Los comentarios metalingüísticos también vehiculizaron la interacción en una situación de recuperar personajes antagónicos de cuentos infantiles conocidos y la lectura en voz alta de la maestra para favorecer un análisis más profundo sobre la oposición y la contrariedad.

En el grupo de primero de Primaria, se observaron también dos fases diferenciadas (ver Figura 3). En la primera, los fragmentos que aparecían tenían la función principal de visualizar y describir los textos haciendo extracción de los pares de contrarios como también la lectura en voz alta. Además, en esta fase se acentuó la escritura activa por parte de los alumnos, ya fueran reescrituras del texto o listas de pares de contrarios. En la segunda fase, se observó la consolidación del vocabulario de los textos trabajados en la primera sesión a partir de la lectura de las listas acumulativas producidas en clase por parte de los alumnos. También incorporó fragmentos de comentarios metalingüísticos de reflexión sobre las preguntas ¿cómo está?, ¿cómo es?, ¿qué hace?, ¿dónde está? y la confección de listas que agrupaban ordenadamente los pares de contrarios para responder a estas preguntas.

\section{Discusión}

El estudio que acabamos de detallar se caracteriza por el aprovechamiento de la competencia lingüística de los niños sobre los contrarios como un contenido de aprendizaje que aborda una doble línea: aprender vocabulario y aprender a leer y a escribir. En la SD se incorporaron diversos pares de contrarios que actuaban como unidades de entrada o de comprensión a través de los textos, pero también como unidades que promovían el análisis metalingüístico cuando el niño consideraba al mismo tiempo los fines comunicativos de los contrarios y su función lingüística y conceptual fuera del contexto de uso. Efectivamente, los resultados evidenciaron que estas situaciones de aprendizaje favorecen que el niño conjugue, por una parte, los procedimientos metalingüísticos necesarios para apreciar,

\begin{tabular}{|c|c|c|c|c|c|c|}
\hline Sesión 1 & Sesión 2 & Sesión 3 & Sesión 4 & Sesión 5 & Sesión 6 & Sesión 7 \\
\hline Texto 1 & Texto 1 & Texto 2 & Texto 3 & Textos 1, 2, 3 & Otros textos & Texto 4 \\
\hline VIS & VOC & VIS & VIS & VOC & LVA \\
\hline & & & & CCOM & \\
\hline
\end{tabular}

\begin{tabular}{|c|c|}
\hline VIS & Visualización \\
\hline LVA & Lectura en voz alta \\
\hline & Comentarios metalingüísticos \\
\hline
\end{tabular}

\begin{tabular}{|l|l|}
\hline VOC & Vocabulario-asociación \\
\hline
\end{tabular}

Fiqura 2. Patrón de evolución de la secuencia didáctica en P5. 


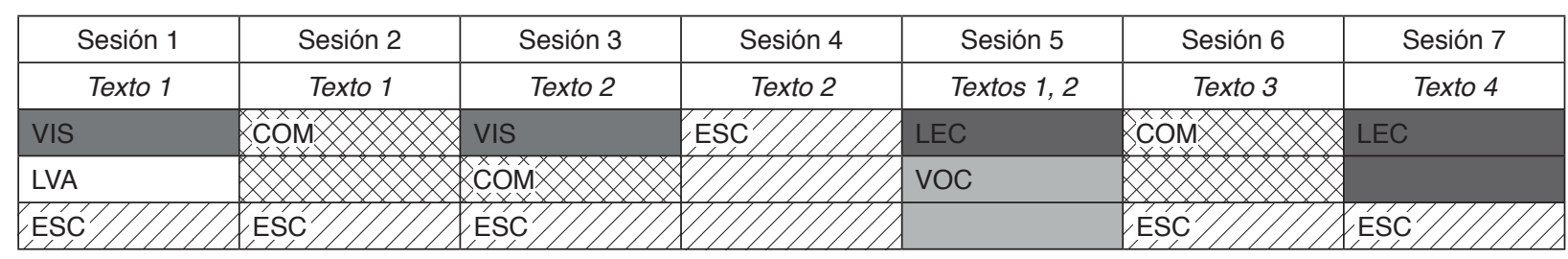

\begin{tabular}{|l|l|}
\hline VIS & Visualización \\
\hline LVA & Lectura en voz alta \\
\hline COM & Comentarios metalingüísticos \\
\hline
\end{tabular}

\begin{tabular}{|l|l|}
\hline VOC & Vocabulario-asociación \\
\hline ESC & Escritura individual \\
\hline LEC & Lectura individual \\
\hline
\end{tabular}

Figura 3. Patrón de evolución de la secuencia didáctica en primero de Primaria.

comprender, recibir y producir pares de ítems que son semánticamente incompatibles, pero que mantienen una relación semántica mínima como bien consideraron Clark (1972) y Murphy (2003). Por otra parte, revelaron que incorporar los contrarios como una unidad escribible permite ampliar y configurar inventarios paradigmáticos en lo oral y en lo escrito como demostraron Teberosky y Portilla (2011).

Comparando las producciones de listas orales y escritas después de la intervención, se encontró una mayor producción oral de contrarios, lo que demostraba un aumento de vocabulario después de la SD. La menor producción de listas escritas en comparación con las orales posiblemente deriva del proceso mismo de construcción de lo alfabético en el que el tiempo y el esfuerzo en la coincidencia entre los grafemas y los fonemas juegan un papel importante en la producción escrita. De todas maneras, la producción de contrarios escritos aumentó después de la SD en comparación con las listas escritas antes de la SD, lo que es indicador de avance en el aprendizaje. Asimismo, la producción de listas escritas se mantuvo más homogénea después de la intervención en comparación con la producción oral. Esto puede ser indicativo de un ritmo de aprendizaje de los dos grupos escolares más homogéneo y un aumento de la capacidad de escritura que puede ser debido al diseño y la potencialidad de las secuencias didácticas. En síntesis, a partir de los resultados se ha constatado que los niños después de la intervención produjeron un mayor número de palabras contrarias en listas orales y escritas por el hecho de que se había ampliado el repertorio.

Sobre el desarrollo de la SD, los patrones identificados reflejan que las tareas encadenadas facilitaron la evolución hacia un análisis de los contrarios más paradigmático a partir de un trabajo activo sobre el vocabulario de los textos que se iba conjugando con un trabajo explícito en los procesos de lectura y escritura. La visualización, la descripción, la interpretación, la comprensión, los comentarios sobre los contrarios, su lectura y su escritura posiblemente activaron la reflexión metalingüística requerida para promover el cambio paradigmático descrito por Nelson (1977) en la comprensión de la lengua. Este cambio, se refleja en el dominio de un plano más centrado en el sistema de la lengua y por ello más metalingüístico y facilitador del aprendizaje inicial del lenguaje escrito como expusieron Cronin (2002) y Watson (1995). Como consecuencia, se ha demostrado la potencialidad de los contrarios como unidad productiva en lo oral y en lo escrito, una unidad intrínsecamente generadora de aprendizaje de vocabulario que se comprende y usa precozmente como evidenciaron Blanche-Benveniste y Ferreiro (1988), Clark (1993), Cruse (1986) y Murphy y Jones (2008).

Con la realización de este trabajo se ponen en evidencia situaciones adecuadas de aprendizaje de la lengua oral y del aprendizaje inicial de la escritura desde el punto de vista evolutivo de la adquisición del lenguaje. Es evidente que al incorporar dinámicas auténticas que dirigen la atención de los niños tanto al punto de vista comunicativo como al punto de vista metalingüístico, el aprendizaje de la lengua escrita puede conjugarse con el aprendizaje y desarrollo del lenguaje en general y con el aprendizaje de vocabulario en particular.

La investigación que se acaba de presentar tiene algunas limitaciones que podrían tenerse en cuenta en posteriores estudios. Por ejemplo, dentro de los aspectos que hay que profundizar encontramos la relación de interdependencia entre lo oral y lo escrito, que podría valorarse con mayor precisión concretando aspectos metodológicos en la recolección de productos escritos y orales. También cabe señalar que el lapso ocurrido entre las tareas individuales de producción de contrarios previas y posteriores a la SD fue extenso y que no se controlaron otras influencias en el aprendizaje del vocabulario, como, por ejemplo, el propio ritmo evolutivo del niño y las experiencias de aprendizaje incidentales. Otro aspecto que hay que considerar es la pertinencia de incluir un grupo escolar equivalente que no recibiera ningún tipo de intervención en el aula, si el objetivo fuese comparar y estudiar el impacto de secuencias didácticas determinadas y aportar a la investigación educativa en este sentido, y que aquí no se ha resaltado dadas las condiciones del diseño del estudio.

\section{Agradecimientos}

Al Centro de Educación Infantil y Primaria «Àngel Baixeras» de la ciudad de Barcelona por su colaboración 
en este estudio, a la profesora Montse Ganga y Joana León.

\section{Referencias}

Aguinaga, G., Armentia, M.L., Fraile, A., Olangua, P. \& Uriz, N. (2004). Prueba de Lenguaje Oral de Navarra, revisada. Madrid: TEA.

Blanche-Benveniste, C. \& Ferreiro, E. (1988). Peut-on dire des mots à l'envers? Une réponse morphologique des enfants de quatre et cinq ans [ $¿$ Podemos decir las palabras al revés? Respuesta morfológica de niños de cuatro y cinco años]. Archives de Psychologie, 56, 155-184.

Carey, S. (1978). The child as word learner. En M. Halle, J. Bresnan, \& G. A. Miller (Eds.), Linguistic theory and psychological reality (pp. 264-293). Cambridge, MA: MIT Press.

Clark, E. (1972). On the child's acquisition of antonyms in two semantic fields. Journal of Verbal learning \& Verbal Behavior, 11, 750-758. doi:10.1016/S00225371(72)80009-4

Clark, E. V. (1993). The lexicon in Acquisition. Cambridge: University Press.

Clark, E. V., Carpenter, K. L., \& Deutsch, W. (1995). Reference states and reversals: Undoing actions with verbs. Journal of Child Language, 22, 633-662. doi:10.1017/S0305000900009983

Cobb, P., Confrey, J., diSessa, A., Lehrer, R. \& Schauble, L. (2003). Design Experiments in Educational Research. Educational Researcher, 32 (1), 9-13. doi: 10.3102/0013189X032001009

Coll, C., Onrubia, J., \& Mauri, T. (2008). Ayudar a aprender en contextos educativos: el ejercicio de la influencia educativa y el análisis de la enseñanza. Revista de Educación, 346, 33-70. Recuperado de http://www.mecd.gob.es/revista-de-educacion/numeros-revista-educacion/numerosanteriores/2008/ re346/re346_02.html

Cronin, V. (2002). The syntagmatic-paradigmatic shift and reading development. Journal of Child Language, 29, 189-204. doi: 10.1017/S0305000901004998

Cruse, A. (1986). Lexical semantics. Cambridge: Cambridge University Press.

Cruse, A. (2010) Meaning in language: An introduction on Semantics and Pragmatics (3a ed.). Oxford: OUP

Croft, W. \& Cruse, A. (2008). Lingüística Cognitiva. (A. Benítez, Trad.). Madrid: Akal

De Corte, E. (Septiembre, 2009). Investigación basada en el diseño: Un enfoque prometedor para cerrar la brecha entre la teoría y las prácticas educativas. Ponencia presentada en el X Congreso Mexicano de Investigación Educativa Veracruz, México.

Dunn, L. M. (1985). Test de vocabulario imágenes Peabody - Adaptación española. Madrid: Mepsa.

Dunn, L. M. \& Dunn, L. M. (1981). Peabody Picture Vocabulary Test - Revised. Circle Pines, MN: American Guidance Service.

Fellbaum, C. (1995). Co-occurrence and antonymy. International Journal of Lexicography, 8, 281-303. doi: $10.1093 / \mathrm{ij} 1 / 8.4 .281$
Ferreiro, E. (2002). Escritura y oralidad: unidades, niveles de análisis y conciencia metalingüística. En E. Ferreiro (Comp). Relaciones de (in)dependencia entre oralidad y escritura (pp. 151-172). Barcelona: Gedisa.

Ferreiro, E. \& Teberosky, A. (1979). Los sistemas de escritura en el desarrollo del niño. México: Siglo XXI.

Goody, J. (1977). La domesticación del pensamiento salvaje. Madrid: Akal.

Jones, S. (2002), Antonymy: A Corpus-based perspective. London and New York: Routledge.

Jones, S. \& Murphy, M. L. (2005). Using corpora to investigate antonym acquisition. International Journal of Corpus Linguistics, 10(3), 401-422. doi:10.1075/ ijcl.10.3.06jon

Justice, L.; Meier, J. \& Walpole, S. (2005). Learning New Words From Storybooks. An Efficacy Study With AtRisk Kindergartners. Language, Speech, and Hearing Services in Schools, 36, 17-32. doi: 10.1044/01611461(2005/003)

Kagan, J. (1984). The nature of the child. New York: Basic Books.

Llach, S. \& De Ribot, M. D. (2010). Contrarios y aprendizaje: preferencia por las diferencias salientes entre objetos. Educar, 46, 107-121. Recuperado de: http:// educar.uab.cat/article/view/87/74

López-Orós, M. \& Teberosky, A. (1998). La evolución de la referencia en catalán en narraciones orales y escritas. Infancia y Aprendizaje, 83, 75-92. doi:10.1174/021037098760403488

Lyons, J. (1977). Semantics. Cambridge, MA: Cambridge University Press.

Muehleisen, V. (1997) Antonymy and Semantic Range in English. (Tesis doctoral no publicada). Northwestern University, Evanston, Illinois. Recuperado de: http://www.f.waseda.jp/vicky/dissertation/index. html

Murphy, G. \& Andrew, J. (1993). The Conceptual Basis of Antonymy and Synonymy in Adjectives. Journal of Memory and Language, 32, 301-319. doi:10.1006/ jmla.1993.1016

Murphy, L. M. (2003). Semantic Relation and the Lexicon: Antonymy, synonymy and Other Paradigms. Cambridge: Cambridge University Press.

Murphy, L. M. \& Jones, S. (2008). Antonyms in children's and child-directed speech.

First Language, 28(4), 403-430. doi: 10.1177/ 0142723713503146

Nelson, K. (1977). The syntagmatic-paradigmatic shift revisited: a review of research and theory. Psychological Bulletin, 84(1), 93-116. doi: 10.1037/00332909.84.1.93

Paradis, C. \& Willners, C. (2006). Antonymy and negation-The boundedness hypothesis. Journal of Pragmatics, 38, 1051-1080. doi: 10.1016/j. pragma.2005.11.009

Paradis, C. \& Willners, C. (2011). Antonymy: From convention to meaning-making. Review of Cognitive Linguistics, 9, 367-391. doi: 10.1075/rcl.9.2.02par

Portilla, C., Peró, M. \& Teberosky, A. (2009). La doble denominación de la sinonimia en el contexto de lo 
escrito. Infancia y Aprendizaje, 32 (3), 277-292. doi: 10.1174/021037009788964196

Rinaudo, M.C. \& Donolo, D. (2010). Estudios de diseño. Una perspectiva promisoria en la investigación educativa. Revista de Educación a Distancia, 22, 1-29. Recuperado de http://www.um.es/ead/red/22

Sénéchal, M. (1997). The differential effect of storybook reading on preschooler's expressive and receptive vocabulary acquisition. Journal of Child Language, 24, 123-138.

Sénéchal, M. (2006). Testing the Home Literacy Model: Parent Involvement in Kindergarten Is Differentially Related to Grade 4 Reading Comprehension, Fluency, Spelling, and Reading for Pleasure. Scientific Studies of Reading, 10, (1), 59-87. doi: 10.1207/s1532799xssr1001_4

Sénéchal, M., \& LeFevre, J. (2014). Continuity and Change in the Home Literacy Environment as Predictors of Growth in Vocabulary and Reading. Child Development, 85, 1535-1551. doi: 10.1111/cdev.12222.

Sepúlveda, A. \& Teberosky, A. (2008). Elaboración de listas a partir de textos y textos a partir de listas. Una actividad para aprender lenguaje escrito. Lectura $y$ Vida, 4, 6-19.

Sulzby, E. (1996). Roles of oral and written language as children approach conventional literacy. En C. Pontecorvo, M. Orsolini, B. Burge, \& L. Resnick (Eds.), Children's early text construction (pp.25-46). Mahwah, NJ: Erlbaum.

Teberosky, A. \& Portilla, C. (2011). Los contrarios en el aprendizaje inicial del lenguaje escrito. Cultura \& Educación, 23(4), 515-531. doi: 10.1174/113564011798392406
Tomasello, M. (2003). Constructing a Language. A UsageBased Theory of Language Acquisition. Harvard: Harvard University Press.

Vuyk, R. (1981). Panorámica y crítica de la epistemología genética de Piaget 1965-1980. Madrid: Alianza.

Watson, R. (1995). Relevance and definition. Journal of Child Language, 22(1), 211-222. doi: 10.1017/ S0305000900009703

\section{Els contraris a l'aula de classe quan s'aprèn a llegir i a escriure}

Resum. En aquest estudi s'analitzen les produccions orals $i$ escrites de llistes de paraules contràries de nens de 5 i 6 anys, i la seva evolució després d'una seqüència didàctica a l'aula de classe. Les paraules contràries van ser el contingut d'aprenentatge quan els nens aprenien a llegir i a escriure seguint el criteri que l'eficàcia de l'ensenyament de la llengua augmenta quan es recolza en les competències lingüístiques dels alumnes. En l'anàlisi, les produccions es van descriure i comparar per determinar diferències entre l'oral i l'escrit, $i$ entre els moments anteriors i posteriors a la intervenció. En la seqüència didàctica es van identificar els processos subjacents a l'aprenentatge de les paraules contràries. Els resultats mostren un increment de vocabulari tant en les tasques orals com en les escrites després de la intervenció, amb algunes diferències entre modalitats que són descrites. Aquest increment s'interpreta a partir dels patrons expressats en les tasques d'aprenentatge, el seu caràcter encadenat i l'evolució de les sessions a través del treball amb textos de literatura infantil que van afavorir la capacitat metalingüistica i les possibilitats d'escriptura i lectura.

Paraules clau: contraris; antonímia; llenguatge escrit; ensenyament; aprenentatge 
